\title{
EFICÁCIA CONSTITUCIONAL: PSEUDO - PROBLEMA
}

\author{
CONSTITUTIONAL EFFECTIVENESS: PSEUDO - PROBLEM
}

\section{Maria Helena Diniz}

\begin{abstract}
Doutora em Teoria Geral do Direito e Filosofia do Direito pela Pontifícia Universidade Católica de São Paulo PUCSP. Livre-Docente e titular de Direito Civil da Pontifícia Universidade Católica de São Paulo - PUCSP, por concurso de títulos e provas. Professora de Direito Civil no curso de Graduação da Pontifícia Universidade Católica de São Paulo - PUCSP. Professora de Filosofia do Direito, de Teoria Geral do Direito e de Direito Civil Comparado nos cursos de Pós-Graduação (Mestrado e Doutorado) em Direito da Pontifícia Universidade Católica de São Paulo -

PUCSP. Coordenadora do Núcleo de Pesquisa em Direito Civil Comparado nos Cursos de Pós-Graduação em Direito da Pontifícia Universidade Católica de São Paulo - PUCSP. Presidente do Instituto Internacional de Direito

(IID). E-mail: mari.santiago@terra.com.br
\end{abstract}

Recebido em: 04/02/2020

Aprovado em: 05/05/2020

RESUMO: Nesta reflexão sobre eficácia da Lei maior, sob a prisma linguístico, que possibilita analisar a norma em sua estreita relação com o fato positivado e com o valor do objetivo, pudemos concluir que não há sob o ângulo pragmático norma constitucional sem eficácia, pois todas têm a possibilidade (maior ou menor) de produzir concretamente efeitos jurídicos e poderão dar azo ao aparecimento de lacunas e de antinomias reais, que exigirão o emprego de técnicas para obtenção da coerência interna do sistema ou a captação de regras de regulagem, atendendo à ideia de segurança jurídica.

Palavras-chave: Semiologia sistema jurídico; eficácia constitucional; lacuna; inconsistência; coerência interna; regras de calibragem; aporia; pseudo problema.

ABSTRACT: In this reflection on the effectiveness of the Federal Constitution, under the linguistic prism, which makes it possible to analyze the norm in its close relationship with the fact positified and with the value of the objective, we could conclude that there is, under the pragmatic angle, no constitutional norm without effectiveness, because all have the possibility (greater or lesser) of producing concrete legal effects and may give rise to the appearance of gaps and real antinomies, which will require the use of techniques to obtain the internal coherence of the system or the capture of regulatory rules, taking into account the idea of legal certainty.

Keywords: Legal system semiology; constitutional effectiveness; gap; inconsistency; internal coherence; calibration rules; aporia; pseudo problem.

SUMÁRIO: 1. Introdução: Eficácia da norma constitucional como um problema teórico-científico e a instrumentalidade técnica do sistema; 2. Eficácia sob uma dimensão pragmática em conexão com o sintática e a semântica; 3. Funções eficaciais das disposições constitucionais; 4. Inconsistência da norma constitucional: técnicas para obtenção da coerência interna do sistema; 5. Polêmica da eficácia constitucional como um pseudo problema ou como uma aporia; Considerações finais; Bibliografia. 


\section{INTRODUÇÃO: EFICÁCIA DE NORMA CONSTITUCIONAL COMO UM PROBLEMA TEÓRICO-CIENTÍFICO E A INSTRUMENTALIDADE TÉCNICA DO SISTEMA}

Procuraremos fazer uma análise técnico-jurídica da eficácia de norma constitucional, fazendo uso de uma perspectiva crítico-epistemológica, que permite uma especulação normativo - fático e axilológica, fundada no tridimensionalismo de Miguel Reale e uma investigação linguística, que conduzirá ao modelo empírico que, por sua vez, acentuará os aspectos funcionais da norma constitucional, visualizando-a como um processo comunicativo, fornecendo uma abordagem de sua eficácia sob a dimensão linguístico-pragmática em conexão com a sintática e semântica.

A semiologia desemboca no pensamento epistemológico-crítico ao estudar seu objeto não como um instrumento de uma comunicação, desvinculado do mundo exterior, mas como uma tecnologia que, apropriando-se do mundo fático-valorativo, coloca-se ao seu serviço. ${ }^{1}$

A questão da eficácia constitucional só se tornou um problema jurídico com a Revolução Francesa, que possibilitou a consolidação de condições sócio-políticas, como soberania nacional e separação de poderes e jurídicas, como a preponderancia de norma constitucional e das leis enquanto fontes de direito, o controle de legalidade e de constitucionalidade das decisões do poder judiciário e principalmente, a concepção do direito como sistema.

O sistema criado pelo jurista seria o "figurino" pelo qual modelar-de-ia a norma constitucional, tendo-se em vista a questão de sua eficácia, ressalvando o caráter preponderante da 2 lei maior

Por que seria suprema a norma constitucional?

Sê-lo-á não só no sentido teórico, por ser a norma-origem, por não existir outra acima dela, como também no sentido sócio-político por decorrer de uma decisão política do povo, titular do poder constituinte ${ }^{3}$, exercendo ou não direito à desobediência civil ou de resistência.

A supremacia da Constituição, envolve o problema do controle de constitunalidade de sua reforma, emenda ou revisão, pois os textos constitucionais devem harmonizar-se com a realidade social cambiante e com valores nela positivados, sob pena de se mumificarem. Necessária se torna a modificação constitucional que ajuste a constituição à vida social, evitando a desarmonia entre o preceito vigente e os valores sociais que acarreta a revolução. Porém tal mudança constitucional deverá seguir as formalidades prescritas pela própria Constituição. Eis o motivo pelo qual a Constituição admite o poder de emendabilidade dentro de certo limites, como o respeito à federação, ao voto direto, secreto, universal e periódico; à separação de poderes e aos direitos e garantias fundamentais $\left(\mathrm{CF}\right.$, art.60 $\left.\S 4^{\circ}\right)$, desde que a reforma não se dê durante a vigência de intervenção federal, de estado de defesa ou de sitio $\left(\mathrm{CF}\right.$, art. $\left.60, \S 1^{\circ}\right) .{ }^{4}$

\section{EFICÁCIA SOB UMA DIMENSÃo PRAgMÁtiCA EM CONEXÃo COM A SINTÁTICA E SEMÂNTICA}

Ante o pluralismo de definições de eficácia apontadas pelos teóricos de direito, decidimos pelo enfoque semiológico, que nos possibilitará ler as significações normativas em sua estreita relação com a realidade fática e com o valor objetivo.

${ }^{1}$ COELHO, L.F Teoria crítica do direito, Curitiba, 1986, p 82.

${ }^{2}$ DINIZ, Constituição de 1988, São Paulo, Atlas, 1989, p61 à 65.

${ }^{3}$ FERRAZ JR, Tércio, Constituinte-assembleia-processo e poder, São Paulo: RT, 1985 p 13-9.

${ }^{4}$ PINTO FERREIRA, Princípios gerais de direito constitucional moderno, São Paulo, RT, 1971, v.1 p.158 e s; LOEWENSTEIN, Teoria de la constitución, Barcelona, Editora Ariel, 1970, p 149-231; SALDANHA, Nelson, Problemática da supremacia constitucional, Revista de Direito Público, 57-58: 110-21, 1981; DINIZ, M.H. Norma constitucional e seus efeitos, São Paulo, Saraiva 1989 p 13-15.

Revista de Direito Brasileira | Florianópolis, SC | v. 24 | n. 9 | p.330-340 | Set./Dez. 2019 
Útil é o recurso à semiologia porque o direito requer alteridade e a comunicação é imprescindível para a convivência social, logo precisa da linguagem para ter existência. ${ }^{5}$

Como na semiose, sempre se encontram relacionados o signo, o objeto denotado pelo signo e determinadas pessoas (emissor e destinatário), a semiótica apresenta três dimensões ${ }^{6}$

a) Sintática, que estuda os signos ou símbolos linguísticos relacionados entre si mesmos, prescindindo dos usuários e das designações.

b) Semântica, que encerra a relação dos signos com os objetos extralinguísticos denotados.

c) Pragmática, que estuda os símbolos linguísticos em relação com os usuários. Como nos ensina Tércio Sampaio Ferraz Jr a pragmática não é uma espécie de procedimento analítico meramente adicional às análises semântica e sintática, mas uma linguística do diálogo por tomar por base a intersubjetividade comunicativa, tendo por centro diretor da análise o princípio da interação, ocupando-se do ato de falar enquanto uma relação entre emissor e receptor, na medida em que for mediada por signos linguísticos. Assim, será possível captar o fenômeno eficacial pelas funções que desempenha no contexto normativo e fazer a leitura ideológica da significação normativa relacionada com outros comandos, com a realidade social, com o valor nela positivado, com seu emissor e com seus endereçados, analisando o papel dos fatores extranormativos nas justificações da eficácia.

Há efeitos de norma constitucional atinentes à relação sintática entre o mandamento constitucional e outras normas. Assim, a eficácia seria a aptidão técnica para produzir efeitos jurídicos. A eficácia é aqui empregada no sentido jurídico. A norma constitucional terá eficácia jurídica se ela tiver condições de aplicabilidade, podendo produzir concretamente seus próprios efeitos, por estarem presentes os elementos normativos idôneos nela ou em outra norma sem que haja necessidade de se ater à sua observância, ou não, pelos destinatários. P. ex a C. F estabelece no art. 44 parágrafo único que o Poder Legislativo é exercido pelo Congresso Nacional, que se compõe da Câmara dos Deputados e do Senado Federal, sendo que cada legislatura terá a duração de quatro anos.

É fato que, devido ao conteúdo de certas normas constitucionais, essas não poderão produzir imediatamente seus efeitos, ante a falta de legislação ulterior exigida por elas, por ex. o art. 37, VII, que requer lei complementar para definir os termos e limites do direto de greve do funcionalismo público. Se está lei não advier, ter-se-á incompletude de norma constitucional, pois a inexistência de disposição normativa requerida, colocar-nos-á ante uma lacuna técnica ${ }^{7}$ que sempre ocorrerá quando houver ausência de uma norma, cuja vigência é condição de eficácia de outra.

a) Existem mecanismos para solucionar lesão a direito individual pela falta de normação ulterior tais como: Mandado de injunção (CF. art. $\left.5^{\circ}, \mathrm{LXXI}\right)$, procedimento pelo qual se visa obter ordem judicial que determina a prática ou a abstenção de ato, tanto da administração pública, como do particular, por violação de direitos constitucionais fundada na falta de norma regulamentadora e

\footnotetext{
${ }^{5}$ CAPELLA, El derecho como lenguage, Barcelona, Ariel, 1968

${ }^{6}$ MORRIS, Semiotic and scientific empirism, in Aclés du Congrès International de Philosophie Scientific, Hermann, 1938, V.1 p 50 a 51; BALAVAL, Les philosophies et leur lenguage, Paris, Gallimard 1952 FERRAZ Jr. Teoria norma jurídica, Rio de Janeiro, Forense, 1978 p.
}

${ }^{7}$ Kelsen, Teoria pura do direito, Coimbra, 1962, V.2 p 111-2

Revista de Direito Brasileira | Florianópolis, SC | v. 24 | n. 9 | p.330-340 | Set./Dez. 2019 
b) Iniciativa legislativa popular (CF art.14. III, $27 \S 4^{\circ}, 29, \mathrm{XI}, 61 \S 2^{\circ}$ ), pois há autorização constitucional para que o povo venha a influir de modo direto no estabelecimento de preceitos normativos, apresentando projetos de lei.

No nível sintático poderá haver efeitos da norma constitucional no tempo relativamente a outras: a) revogando, imediatamente, devido a sua supremacia, norma que com ela colidirem; b) recepcionando as que com ela não conflitarem, pois a nova $\mathrm{CF}$ não repudiará normas anteriores se com ela forem materialmente compatíveis, dando assim continuidade às relações sociais sem necessidade de edição de outras leis ordinárias ou infraconstitucionais; c) condenando a repristinação, pois não haverá restauração eficacial de lei ordinária, se ela já perdeu sua eficácia sob a égide de uma Constituição, não mais virá a readquiri-la com o novo texto constitucional, salvo se houver expressa disposição normativa nesse sentido; d) operando a desconstitucionalização, porque se houver norma constitucional anterior disciplinadora de matéria que não foi objeto da nova regulamentação constitucional, ela não perderia sua vigência, nem sua eficácia, pois continuaria em vigor, não mais na veste de norma constitucional, mas na de lei ordinária, devido ao princípio da continuidade das normas compatíveis. A desconstitucionalização nada mais é senão a recepção pelo novo texto constitucional, como leis ordinárias das antigas disposições constitucionais que não são objeto de nova carta. ${ }^{8}$

A eficácia social é alusiva à relação semântica entre a norma constitucional, (signo), não só com a realidade fática a que se refere, mas também com valores positivos, que são os objetos denotados. Sob o ângulo semântico, a norma constitucional eficaz seria de fato obedecida, por ser aplicada concretamente, visto ser adequada à realidade social e os valores positivos.

Por outras palavras considerar-se-á eficaz socialmente o preceito constitucional que encontrar na realidade fática e nos valores objetivos as condições de sua obediência ${ }^{9}$, sendo efetivamente aplicada, ou observada, pelos órgãos com competência normativa.

Todavia, a CF contém disposições inaplicáveis, por ex. a art. $100 \S 1^{\circ}$ prescreve que "é obrigatória a inclusão no orçamento das entidades de direito público de verba necessária ao pagamento de seus débitos constantes de precatórios judiciários, apresentados até primeiro de Julho, data em que terão atualizados seus valores, fazendo-se o pagamento até final do exercício seguinte", porém, na verdade, quase nunca as entidades pública incluem nos seus orçamentos tal verba.

A norma tem eficácia jurídica (sintática), embora não tenha a social, por ser ineficaz semânticamente, por estar desligada da realidade social. Surgirá então a lacuna ontológica.

Para que não se dê essa modalidade de lacuna, a norma constitucional deverá ser um reflexo da situação social existente, evitando-se, assim o perigo de um hiato entre o social e o jurídico, que levaria à sua ineficácia semântica por falta de ressonância no seio da coletividade, que conduzirá à sua inaplicabilidade ${ }^{10}$.

Se houver inadequação do texto constitucional em relação a um valor objetivo ter-se-á lacuna axiológica, pois não haverá sua aplicação ou obediência pelo órgão competente, sendo inefetiva semanticamente. No art. 37, VII da CF que garante a greve de funcionalismo público, cujo exercício dependerá de lei complementar, apresenta a lacuna técnica e a axiológica.

O fenômeno greve está condicionado não só à sua realidade sociológica, mas sobretudo aos valores. A institucionalização constitucional da greve dos funcionários públicos, dependente de regulamentação de seu exercício, é um recurso anti-social, incompatível com o regime

\footnotetext{
${ }^{8}$ DINIZ, A norma constitucional... cit, p. 28, 29, 40, 41, 47 a 56; BASTOS, Celso Curso de direito constitucional, SP, Saraiva,1984. p 28

${ }^{9}$ FERRAZ JR, Regras para eficácia constitucional Revista da $O A B$, p. 26.

${ }^{10}$ CALERA, La estrutura lógica-real de la norma jurídica, Madrid, 1969, P.. 26; COING, Fundamentos de Filosofia del dereche, Barcelona, Ariel, 1961, p. 244; REALE, Filosofia do direito, São Paulo, Saraiva, 1982 p. 606. Diniz, A norma constitucional... cit p.58 a 61 .
} 
estatutário a que se subordinam os agentes públicos, contrário ao fim e à sobrevivência do Estado. Ante as desordens e os graves prejuízos que acarreta à sociedade e ao povo e a injustiça ou situação indesejável, que desencadeia, poderá gerar no sistema uma lacuna axiológica.

Como toda norma pressupõe um emissor e um destinatário, será preciso analisar o texto constitucional sob o prisma pragmático, pelo qual ele será eficaz se, ao incidir sobre o constituinte e os órgãos com competência normativa (três poderes) vier a produzir, concretamente, efeitos jurídicos, por estarem aquelas pessoas envolvidas em cartas situações fático-valorativas a que se refere $^{11}$. Essa modalidade eficacial só se completa integrando o significado de eficácia social (semântica), vinculando-se a um ato de aplicação ou de observância da norma constitucional pelos seus destinatários, que podem conduzir-se, ou não, de acordo com ela, e de eficácia jurídica (sintática) tendo condições de aplicabilidade, podendo, então, produzir os seus efeitos; Sob o ângulo pragmático o que importa é a relação metacomplementar da autoridade e as condições de aplicabilidade, exigibilidade ou executoriedade da norma, mesmo que ela seja regulamente desobedecida, abarcando assim nível sintática e semântica (possibilidade de desobediência) ${ }^{12}$.

A pragmática está, intimamente, conexa não só às relações sintáticas e semânticas das normas constitucionais, mas também à sua relação funcional de influir no comportamento do destinatário, que pode obedecê-los ou não ${ }^{13}$.

Eis porque se diz que liberdade e direito são uma mesma coisa. A norma jurídica tem como denominador comum a liberdade ${ }^{14}$ de seu destinatário de cumpri-la, ou não. Logo, a norma constitucional está sujeita à prudência objetiva do poder constituinte, exigida pelo conjunto das circunstâncias fático-axiológicas em que se acha seus destinatários, que podem obedecê-la ou desobecê-la. O sucesso da norma constitucional diz respeito à possibilidade da consecução dos objetivos pretendidos com sua edição, que podem estar numa concreção efetiva (obediência), ou na postergação de seus efeitos para momentos oportunos.

Nós há sob o ângulo pragmático norma constitucional sem eficácia. Todo e qualquer preceito constitucional que contiver um mínimo de eficácia tem a possibilidade de produzir, concretamente efeitos jurídicos. ${ }^{15} \mathrm{E}$ é preciso lembrar que as lacunas constitucionais são preenchidas pelos critérios normativos dos arts. $4^{\circ}$ e $5^{\circ}$ de LINDB: analogia, costume, princípios gerais de direito em busca da finalidade social e do critério do justum.

\section{FUNÇÕES EFICÁCIAS DAS DISPOSIÇÕES CONSTITUCIONAIS}

As normas constitucionais apresentam três funções eficácias. ${ }^{16}$

Alguns preceitos constitucionais têm a função de bloqueio a futura atividade do órgão público competente para produzir normas, por conterem fins e princípios, que vinculam a autoridade competente, limitando a sua ação, visto que impedem a emissão de comandos que não sejam incompatíveis, paralisando a eficácia. Podem ter essa eficácia negativa as normas com eficácia absoluta, plena, a relativa dependente de complementação legislativa declaratória de princípios institutivos como os arts. $2^{\circ}, 5^{\circ}, 14,22,25 \S 3^{\circ}, 60 \S 4^{\circ}, 148$, I.II 153, 170, I a IX, etc..

As normas que têm essa função conferem: a) o direito de exigir, perante, o Poder judiciário a declaração de inconstitucionalidade de atos normativos contrários a elas, sem que conteúdo, tenha havido qualquer lesão a direito individual; b) o direito de obter sentenças ou decisões judiciais conforme ao seus comandos ${ }^{17}$. c) o uso pelo intérprete, em certas circunstâncias, do argumento $a$

\footnotetext{
${ }^{11}$ FERRAZ JR, Teria da norma jurídica, Rio de Janeiro, Forense, 1978.

${ }^{12}$ FERRAZ JR, Teoria da norma, cit. p. 3, 117, 118.

${ }^{13}$ COELHO, Teoria crítica do direito. Curitiba, 1986 p. 69 a 77.

${ }^{14}$ DORANTES, Que es el derecho; México, 1962, p. 232 e 233.

${ }^{15}$ DINIZ, A norma constitucional, cit... p.73.

${ }^{16}$ FERRAZ JR, Revista OAB 26-27; Diniz, A norma... cit. P. 105 a 110

${ }^{17}$ BANDEIRA DE MELLO, Eficácia das normas constitucionais sobre justiça social RDP, $57 / 58$ p. 243
}

Revista de Direito Brasileira | Florianópolis, SC | v. 24 | n. 9 | p.330-340 | Set./Dez. 2019 
contrario, logo se proíbe a conduta A, qualquer comportamento diferente de A estará permitido, implicitamente. d) a autorização, havendo ausência de regulamentação infraconstitucional, de iniciativa legislativa popular e do mandado de injunção.

Têm função eficacial de programa as normas constitucionais que pretendendo a consecução de fins sociais do Estado, tutelando-os traçam certos programas de ação, embora sejam dependentes de integração legislativa (ex. arts. 205, 215, 218 e 226.) E para que possam produzir concretamente efeitos jurídicos visados contém mecanismos hábeis, que permitem a aquisição de sua eficácia, como integração legislativa por iniciativa popular, a ação de inconstitucionalidade por omissão e o mandado de injunção.

Têm eficácia jurídica porque:

a) impedem que o legislador comum edite normas um sentido oposto ao direito assegurado pela constituinte;

b) impõem um dever político ao órgão com competência normativa;

c) informam a concepção estatal ao indicar suas finalidades sociais e os valores objetivados pela sociedade;

d) condicionam a atividade discricionária da administração e do judiciário;

e) servem de diretrizes teleológicas para a interpretação e aplicação jurídica (subsunção, integração de lacunas e correção de antinomias reais);

f) estabelecem direitos subjetivos por impedirem comportamentos antagônicos a elas ${ }^{18}$

Existem mandamentos constitucionais que apresenta a função eficacial de resguardo, porque o direito neles comtemplado pode ser restringido por eles mesmos ou, futuramente, por lei p ex. CF arts. $5^{\circ}$ VIII, XII, XIII, XIV, XXIV, LXVII, 15, 37, I, 84, XXVI, 139, 148, 170. Parágrafo único; 184.

Para que se manifeste o exercício dessa função ter-se-á não só a iniciativa legislativa popular, como também o mandado de injunção. ${ }^{19}$

\section{INCONSISTÊNCIA DA NORMA INCONSTITUCIONAL: AS TÉCNICAS PARA OBTENÇÃO DA COERÊNCIA INTERNA DO SISTEMA}

O problema do conflito normativo real ou da inconsistência entre normas igualmente fortes repercutirá na eficácia, pois poderá provocar a revogação p. ex. mediante derrogação, ou seja edição de uma $3^{\circ}$ norma que opta por uma delas por incompatibilidade ou a interpretação corretiva para que haja coerência lógica do sistema. ${ }^{20}$

Realmente por ser impossível deslocar uma das normas como a mais forte $\left(\mathrm{CF}\right.$ art. $5^{\circ}, 100$, ADT 33), por não haver critério normativo (hierárquico, especialidade e cronológico), que permita decidir entre elas, o aplicador terá que lançar mão dos arts. $4^{\circ}$ e $5^{\circ}$ de LINDB, resolvendo a antinomia real no caso sub judice. Se possível for a solução por um daqueles critérios, a antinomia será aparente, e solucionada por mera subsunção.

O rigor cientifico requer que o jurista, ao estudar normas, crie epistemologicamente o sistema de forma que haja coerência interna e unidade. Haverá unidade se a cadeia normativa for conforme à norma-origem $(\mathrm{CF})$, e conseguintemente ter-se-à coerência. Se advir norma conflitante com a lei maior, o sistema apresentará outra série normativa, perdendo sua unidade e coerência interna, por conter duas normas-origens incompatíveis entre si, visto que a lei inconstitucional

\footnotetext{
${ }^{18}$ SILVA, José Afonso da Norma constitucional, in A norma jurídica (Sérgio Ferraz, coordenador). Rio de Janeiro, Freitas Bastos, 1980 p. 48; FERRAZ JR., Introdução ao estudo do direito, SPaulo, Atlas, 1988 p.125.

${ }^{19}$ DINIZ, Norma... cit. p. 105.110)

${ }^{20}$ ENGISCH, Introdução ao pensamento jurídico, Lisboa, Calouste, Gulbenkian 1964 p. 253; Gavazzi, Delle antinomie, Torino, Giappicheli: 1959, p. 166-8.
}

Revista de Direito Brasileira | Florianópolis, SC | v. 24 | n. 9 | p.330-340 | Set./Dez. 2019 
posicionar-se-à como uma norma-origem ${ }^{21}$, produzindo todos os efeitos jurídicos pretendidos com sua edição.

Como tentativa para obter sua unidade e coerência lógica, o próprio sistema apresenta técnicas tais como $^{22}$

a) ação direita de inconstitucionalidade contra ato ou omissão contrários a $\mathrm{CF}$, sem que haja lesão a direito individual (CF, arts. 103, I a IX, § $\left.2^{\circ}, 102, \mathrm{I}, a\right)$ para obter a invalidação da lei em tese. Todavia, o judiciário não terá o poder de retirar-lhe a eficácia, pois competirá ao Senado Federal suspender, total ou parcialmente, a sua execução se declarada inconstitucional (CF, art.52, X);

b) pedido de medida cautelar nas ações direitas de inconstitucionalidade para paralisar a eficácia da norma inconstitucional durante a pendência do julgamento (CF, art. 102, I, p);

c) declaração de inconstitucionalidade pelo judiciário contra ato legislativo, executivo (federal, estadual ou municipal) por meio de via de exceção, ao solucionar casos concretos. As decisões declaratórias de inconstitucionalidade poderão em hipótese de lesão a direito individual advir incidentalmente de remédios jurídicos como:

- mandado de injunção (CF arts. 5, LXXI, 102, I, d, II, a; 105, I, h), ocorrendo omissão legislativa prejudicial ao exercício de direito e liberdade constitucional e de prerrogativa inerente à sua nacionalidade e cidadania, o órgão judicante decidirá a lide, aplicando ao caso sub judice os arts. $4^{\circ}$ e $5^{\circ}$ da LINDB;

- habeas corpus (CF, arts. 5', LXIX, 102, I, d, i, II, a; 105 I, c, II, a; 108, I, d; 109 VII) instituto de direito processual constitucional para a defesa de liberdade pessoal violada ou ameaçada por ato ilegal ou inconstitucional de autoridade pública ou particular ${ }^{23}$;

- mandado de segurança, (CF, art. $5^{\circ}$ LXIX, LXX, a, b; 102, I, d, II a, 105, I, b, II b; 108, I, c; 109, VIII) cabível contra direito liquido e certo ameaçado ou violado de pessoa física ou jurídica, por ato ou omissão ilegal ou inconstitucional, inclusive se praticado por autoridade pública ou agente dos serviços delegados do poder público. O mandado de segurança experimentou ampliação na legitimidade para sua impetração. A nova carta, ao criar o mandado de segurança coletivo, autorizou a sua impetração por entes representativos (partidos políticos, sindicatos, associações, entidades de classe) na defesa dos interesses de seus membros ou associados ${ }^{24}$;

- ação popular (CF, art. $\left.5^{\circ}, \mathrm{LXXIV}\right)$, para que possa provocar o pronunciamento do judiciário sobre atos ilegais ou inconstitucionais, comissivos ou omissivos, lesivos ao patrimônio público, condenando os responsáveis ${ }^{25}$;

- habeas-data (CF, art. 5, LXXII) que é ação sumárias e especial para assegurar o conhecimento de informações relativas à pessoa de impetrante, constantes de registros ou bancos de dados de entidades governamentais ou de caráter público (habeas data preventivo) e para retificação de dados inverídicos ou incorretos, existentes nos registros informativos, quando não se preferir fazê-lo por processo sigiloso, judicial ou administrativo (habeas data corretivo). Trata-se de remédio para garantir os direitos à honra, à tranquilidade, ao patrimônio, à privacidade, tutelados constitucionalmente,

\footnotetext{
${ }^{21}$ FERRAZ JR, Teoria da norma jurídica, Rio de Janeiro, Forense, 1978 p. 135 e segts.

${ }^{22}$ BRITTO, C.A. O problema lacuna jurídica no direito constitucional brasileiro. Trab. apresentado no mestrado da PUCSP, 1981 p. 37-44; Diniz, norma... cit. p. 119-132

${ }^{23}$ MARQUES, J.F. Elementos de direito processual penal, Rio de Janeiro, 1965, vol. 4, p. 367-8; Ackel Filho, Diomar, Writs constitucionais, SPaulo, Saraiva, 1988, p.31, 38, 43; PINTO FERREIRA, Habeas Corpus, Enciclopédia saraiva do direito, v. 40, p. 31, 38 e 43; Tucci, Habeas corpus a mandado de segurança, Enciclopédia saraiva do direito, vol. 40, p. 412 e setgs.

${ }^{24}$ ACKEL FILHO, Writs, cit. 3, 61-3-83-86-7;

${ }^{25}$ SEABRA FACUNDES, da Ação popular, RF, n. 62:6; SILVA, José Afonso, Aplicabilidade da ação popular constitucional, SPaulo, 1968.
} 
contra atos praticados por órgãos públicos ao anotarem e registrarem informações sobre a pessoa, pois todos aqueles valores poderão ser vulnerados por informação errônea. Assim, se alguém dispuser de um dado inverídico ou incorreto contido no registro, ou quiser obter informes pessoais constantes de registros ou banco de dados de entidades governamentais ou de caráter público, não logrando o pretendido por meio extrajudicial, autorizado estará pela CF a impetrar o habeas data. Desse direito ao conhecimento dos dados registrados poder-se-á deduzir outros como o fazem Canotilho, Vital Moreira e Leda Pereira de Mota $^{26}$ que são: o direito de acesso consistente no direito de obter aqueles dados pessoais constantes em registros de órgãos públicos; o direito de esclarecimento, pois a entidade depositária daqueles informar tem o dever de informar com que finalidade os coletou; o direito de contestação, visto que o impetrante poderá discutir a veracidade das informações contidas naqueles bancos de dados de entidades governamentais, e o direito de atualização porque haverá possiblidade de suprimir, incluir ou retificar dados desatualizados.

d) analogia, costume e princípios gerais de direito (LINDB, art. $4^{\circ}$ e $5^{\circ}$ ) para a solução das hipóteses em que advirem lacunas.

e) respeito ao ato jurídico perfeito, ao direito adquirido e à coisa julgada $\left(\mathrm{CF}\right.$, art. $5^{\circ}, \mathrm{XXXVI}$; LINDB, art. $6^{\circ}$ ), a revogação de normas por outras da mesma hierarquia ou de escala superior (LINDB, art. $2^{\circ}$ ) e a prevalência de norma pela sua especialidade $\left(\mathrm{CF}\right.$, art. $\left.5^{\circ}\right)$.

O sistema criado pelo jurista, portanto tenderá a evoluir, exercendo um papel moderador, sob pena de o direito converter-se num fator inerte na evolução social e o jurista num defensor de um estado de coisas já superado. Assim, ao exercer sua tarefa sistematizadora, o teórico do direito deverá demonstrar, na sua atividade hermenêutica, quais o mecanismos mais convenientes para a consecução dos efeitos jurídicos perseguidos pela norma constitucional ao ser aplicada pela autoridade competente. ${ }^{27}$

De que serviriam tais técnicas se forem insuficientes para assegurar a unidade e a coerência interna do sistema? Isso poderá ocorrer porque todo destinatário normativo poderá obedecer ou não à norma constitucional, de sorte que, por ex., sempre será possível, a existência de uma lei inconstitucional, elaborada irregularmente pelo órgão competente. O sistema deverá, então, regular sua estrutura para que possa conviver com aquela norma refratária àqueles mecanismos, recepcionando-a, temporiamente, até sua declaração de invalidade e suspensão de sua executoriedade, prestigiando, assim a autoridade que a emitiu ${ }^{28}$. Para isso o jurista deverá captar as seguintes regras de calibragem ${ }^{29}$ ínsitas no sistema por ele criado epistemológicamente: a) "não se pode deixar de obedecer comando de poder público, competente, alegando sua invalidade", deduzida do princípio da presunção juris tantum da legitimidade dos atos normativos dos órgãos públicos, para manter dessa maneira a eficácia de preceito inconstitucional; b) "deve-se respeitar a coisa julgada", ante a presunção absoluta jure et de jure de veracidade, absorvendo a possível inconstitucionalidade, que, porventura, houver em decisão judicial.

Há uma automática autorregulagem do sistema normativo criado pelo jurista, atendendo à ideia de segurança jurídica, pois não se poderia negar, sem que se causasse perturbação social, a aplicação de uma norma jurídica emitida pelo poder competente, por ser inconstitucional.

\footnotetext{
${ }^{26}$ MOTA, Habeas data, porãduba, 26-10-1988 p.2; ACKEL FILHO, op. cit. p. 113-37;

${ }^{27}$ PICAZO, Luiz D. Experiencias jurídicas y teoria del derecho, Barcelona, Ariel, 1973, p. 303 e 304.

${ }^{28}$ BRITTO, op. cit. p. 21 e 22.

${ }^{29}$ FERRAZ JR, Introdução do estudo do direito, SPaulo, Atlas, 1988 p. 175 e 176; Britto, op. cit. 47-52; Diniz, norma cit. p. 132.
} 


\section{POLÊMICA DA EFICÁCIA CONSTITUCIONAL COMO UM PSEUDO PROBLEMA OU COMO UMA APORIA}

A problemática da eficácia constitucional poderia ser considerada pela cientista do direito como um pseudo problema ${ }^{30}$, uma falsa questão não só ante o principio de não contradição lógica , que norteia as asserções do jurista, imprescindível pela exigência de unidade e de coerência interna do sistema, como também pela consideração do mínimo de eficácia como critério determinante da configuração daqueles conceitos. Todavia, na verdade, parece-nos, que estamos também diante de uma autêntica aporia, de uma questão que se perpetuará sempre como um problema.

Vão seria admitir a inexistência do problema conceitual da eficácia da norma constitucional em razão do aspecto multifário e dinâmico do fenômeno jurídico, pelas naturais limitações da condição humana, que impedem ao constituinte a possibilidade de prever todas as situações presentes e futuras, que poderão cair sob o império da Lei Maior e, como se isto não fosse suficiente, a contínua criação, que a vida contém ${ }^{31}$, deixará sempre a norma constitucional fora de adequação em relação à realidade fático-social e aos valores nela objetivados, daí surgirem os conflitos normativos, as inconstitucionalidades, as lacunas etc... enfim, numa só palavra, a ausência de eficácia sociológica. O que gerará a necessidade de correção das antinomias reais, de integração das lacunas axiológicas ou ontológicas, de regulagem do sistema etc..

O termo eficácia esconde ideias díspares, consistindo num dubium, ou seja, numa questão aporética. Densa é a problemática que o envolve, já que os teóricos o abordam cada qual sob uma perspectiva diversa, de sorte que se terá várias repostas, segundo o critério analítico adotado. Apontamos aqui somente uma diretriz sob o prisma semiológico, tendo por suporte o tridimensionalismo jurídico de Miguel Reale.

\section{CONSIDERAÇÕES FINAIS}

A guisa de conclusão podemos dizer que:

a) A norma constitucional deverá produzir concretamente os efeitos jurídicos visados com sua edição, subornando-se a um processo fático-valorativo, apesar de poder gerar lacunas e antinomia real.

b) A ideia de norma constitucional sem qualquer eficácia deverá ser rejeitada no ângulo pragmático em conexão com o sintático e semântico.

c) O conhecimento cientifico-jurídico deverá, ao apreender unitária e coerentemente os dados jurídicos (norma, fato e valor) integrantes do sistema criado epistemologicamente, volver os olhos aos mecanismos por ele apresentados e captar as regras de regulagem nele implícitas, quando aquelas técnicas forem insuficientes para assegurar a supremacia da carta magna e para manter a unidade e coerência logica do sistema;

d) O reconhecimento da insuficiência das técnicas de controle de constitucionalidade, o desprestígio do princípio da unidade e coerência interna e a incorporação no sistema de regras de calibragem, exaltarão a missão de interprete e do aplicador da norma vigente, principalmente no que concerne à produção concreta de seus efeitos jurídicos, colimando assim seu desiderato.

e) A nossa opinião, exarada neste artigo, emitida tendo por base a semiologia e a teoria tridimensional, não deve ser considerada como um pronunciamento final, pois, não há nem

\footnotetext{
${ }^{30}$ LASTRA, Que es el derecho... La Plata, Platense, 1972, p. 347.

${ }^{31}$ PICARD, O direito puro. Lisboa, Ibero-americana, 1942, p.32; Diniz, norma... cit. p. 95-103; Gardiol, Introducción a una teoria general del derecho, 1975, p. 234; REALE, lições preliminares de direito. SPaulo, Bushatsky, 1973, p.300.
} 
haverá entre os autores resposta unânime, devido às inúmeras concepções de sistema e a pluridimensionalidade do direito que, por conter múltiplos elementos heterogêneos, dificultará uma abordagem unitária, de modo que, podemos afirmar, com certeza, que o problema eficacial da norma constitucional continuará sempre aberto constituindo de um desafio para o século XXI. ${ }^{32}$

\section{BIBLIOGRAFIA}

ACKEL FILHO, Diomar. Whits constitucionais. SPaulo: Saraiva, 1988.

BALAVAL. Les philosohies et leur linguage. Paris: Gallimard, 1952.

BANDEIRA DE MELLO. Eficacia das normas constitucionais sobre justiça social. RDP, 57/58: 243 e segts.

BASTOS, Celso. Curso de direito constitucional. SPaulo: Saraiva, 1984.

BRITTO, C.A. O problema da lacuna jurídica no direito constitucional brasileiro. Trabalho apresentado no curso de mestrado da PUCSP em 1981.

CALERA. La estructura logico-real de la norma jurídica. Madrid, 1969.

CAPELLA. El derecho como lenguage. Barcelona: Ariel, 1968.

COELHO, L.F. Teoria crítica do direito. Curitiba, 1986.

COING. Fundamentos de filosofia del derecho Barcelona: Ariel, 1961.

DINIZ, M.H. Constituição de 1988: legitimidade, vigência, eficácia e supremacia. SPaulo: Atlas, 1989.

DINIZ, M.H. A norma constitucional e seus efeitos. SPaulo: Saraiva, 1989.

DORANTES. Que es el derecho. México, 1962.

ENGISCH. Introdução a pensamento jurídico. Lisboa: Calouste-Gulbenkian, 1964.

FERRAZ JR. Tércio S. Constituinte Assembleia, processo e poder. SPaulo: RT, 1985.

FERRAZ JR. Tércio S. Teoria da norma jurídica. Rio de Janeiro: Forense, 1978.

FERRAZ JR. Tércio S. Direito, retórica e comunicação. SPaulo: Saraiva, 1973.

FERRAZ JR. Tércio S. Regras para eficácia constitucional. Revista OAB.

\footnotetext{
${ }^{32}$ Sobre o assunto. DINIZ, M.H. Vigência e eficácia da norma constitucional, Constituição de 1988: Legitimidade,
} vigência, eficácia e supremacia. SPaulo. Atlas, 1989 p. 59 a 88. 
FERRAZ JR. Tércio S. Introdução ao estudo do direito. SPaulo: Altas, 1988.

GARDIOL. Introducciòn a uma teoria general del derecho. 1975.

GAVAZZI. Delle antinomie. Torino: Giappicheli, 1959.

KELSEN. Teoria pura do direito. Coimbra, 1962.

LASTRA. Que es el derecho. La Plata: Platense, 1972.

LOEWENSTEIN. Teoria de la constitución. Barcelona: Ariel, 1970.

MARQUES, J.F. Elementos de direito processual penal. Rio de Janeiro, 1965.

MORRIS. Semiotic and scientific empirism. Actes du Congrès International de philosophie scientific, Hermann, 1938, v.1.

MOTA, Leda P. da. Habeas data. Porãduba, 26/10/1988.

PICARD, O direito puro. Lisboa: Ibero-americano, 1942.

PICAZO. Experiencias jurídicas y teorias del derecho. Barcelona: Ariel, 1973.

PINTO FERREIRA. Princípios gerais de direito constitucional moderno. SPaulo: RT, 1971.

PINTO FERREIRA. Habeas Corpus. Enciclopédia Saraiva do direito, v. 40.

REALE, Miguel. Filosofia do direito. SPaulo: Saraiva, 1982.

REALE, Miguel. Lições preliminares de direito. SPaulo: Bushatsky, 1973.

SALDANHA, N. Problemática da supremacia constitucional. Revista de direito público, 57/58: 110-21 (1981).

SILVA, José Afonso da. Norma constitucional. in A norma jurídica (coord. Sergio Ferraz). Rio de Janeiro: Freitas Bastos, 1980.

TUCCI. Habeas Corpus e mandado de segurança. Enciclopédia Saraiva do direito. v.40. 